\title{
Design and Development of Flood Disaster Game-based Learning based on Learning Domain
}

\author{
Nur Atiqah Zaini, Siti Fadzilah Mat Noor, Syafiah Zahra Mohd Zailani
}

\begin{abstract}
Flood disaster game-based learning provides interactive learning through game-oriented application. Flood disaster game-based learning helped to promote the awareness by guiding them on right actions taken seriously when real flood disaster occurred. In order to improve the preschool children's motivation and engagement to learn flood disaster education, the development of the application focused on animation and audio to draw their attention span. In fact, the elements of game and game factors were applied to bring fun and excitement while learning too. This study was conducted for the preschool children to educate them in flood disaster issues. Therefore, the model development of flood disaster game-based learning involved five phases: analysis, design, development, implementation and evaluation. As a result, the flood disaster game-based learning affected the preschool children's cognitive, psychomotor and behavior. Based on these learning domain showed that gaming environment affected their ways of learning. Therefore, the usability evaluation evaluated that the learnability application helped in exposing the preschool children towards flood disaster issues and problem solving.
\end{abstract}

Keywords : Flood disaster, Game-based learning, Learnability, Preschool Children.

\section{INTRODUCTION}

In recent years, various natural disasters occurred in many places all over the world such as flood, landslides, tsunamis, fire and earthquake. These natural disasters are the leading causes that threaten lives of human who are particularly exposed to danger. Traumatically injured people had difficulties to save themselves or others due to lose consciousness and delay actions. By implementing training and learning to people in the form of game-oriented application or digital games help them to gain knowledge and experience the mock natural disasters [1]. These lead to allow better understanding of extremely dangerous environments with the exposure on natural disasters among

Revised Manuscript Received on April 02, 2020.

* Correspondence Author

Nur Atiqah Zaini*, Business Development Unit, Signature Trust Limited, 87000, Federal Territory of Labuan, Malaysia. Email: nuratiqahhjzaini@siswa.ukm.edu.my

Siti Fadzilah Mat Noor, SOFTAM, Research Center For Software and Technology, Universiti Kebangsaan Malaysia, 43600 Bangi Selangor, Malaysia. Email: fadzilah@ukm.edu.my

Syafiah Zahra Mohd Zailani, SOFTAM, Research Center For Software and Technology, Universiti Kebangsaan Malaysia, 43600 Bangi Selangor, Malaysia. Email: syafiahzailani@gmail.com

(C) The Authors. Published by Blue Eyes Intelligence Engineering and Sciences Publication (BEIESP). This is an open access article under the CC BY-NC-ND license (http://creativecommons.org/licenses/by-nc-nd/4.0/)
people.Addressing this issue, natural disasters affected work, lives, education and abilities. In term of conveying the information to people is the most crucial part where they are exposed and trained well to face natural disasters. Providing training in the real situation consumed time and expensive costs. However, people tend to take training not seriously enough and may cause injuries among them. Training eventually helped people to be alert and give the responses in a very short period of time. Thus, the development of game-based learning and serious games showed the great potential of reducing injuries, overcome drawback and easy to create the emergency scenario artificially using computers [2], [3]. Therefore, advances in technology have opened a wide range of opportunities by using computer simulations in teaching and learning.

Meanwhile, digital games consisted of serious games, educational games and entertainment games. Extending to this research, few games developed for training people on natural disasters awareness should be concerned. Mach investigated on serious gaming of raising awareness for retention measures and flood disasters [4]. Game-initiated learning as an educational method provided a great potential in conveying information and knowledge on disaster management [5]. In addition, Tsai et al. developed a flood game to encourage players' active learning through exploration and investigated on behavior of the players. The effectiveness of a flood disaster game to educate the younger generation demonstrated the experience of enjoyment when learning [6]. These educational games helped to promote the flood disaster awareness by guiding them on right actions of disaster preparations and preventions.

By giving the basic education to the younger generation especially preschool children led them learn on the risk of flood disaster. There were few challenges faced by the preschool students on flood disaster education such as delivering the information that attracted their attention and motivation through learning. Enhancing the preschool children's learning motivation was the crucial part due to their short attention span of learning [7]. Hence, the rise of game-based learning has been developed as a potential way to engage a new generation of classroom learners especially the youngsters. Nowadays, the mobile computer industry that invented smartphones and tablet computers has flourished the markets. The functions embedded in the technologies enable the users to access information easily.

Blue Eyes Intelligence Engineering 
Thus, by developing the digital training helped to increase knowledge and awareness of the citizens on river flooding disaster [8]. The implementation of digital training of flood disaster using smartphones helped the decision makers to manage the crisis.

In addition, flood disaster can be destructive by affecting the environments and people that categorized into human-made and natural disasters. The society must aware about the disaster by providing adequate preparations and response approaches. Hence, well-prepared in every situation will eventually minimize the impacts of disasters that influence their lives especially the children [9]. Recent years, serious game and simulation have been massively adopted in training and learning. Meanwhile, game-based learning has attracted learners through game-oriented application to engage the children during learning session.

The use of technology itself helped in promoting flood disaster education. Smartphones, tablets and computers are used to explore the children's capabilities of cognitive, psychomotor and behavior in order to learn flood disaster education. Nowadays, children adapt well with the use of technologies in learning through interactive games and learning applications. These technologies provide the interactive tools to draw their attention that bring excitement to them. Different ages affect the children's abilities because of the growth development processes. Therefore, learning flood disaster education led them to experience fun and improve knowledge through development of game-based learning.

In fact, multimedia components were applied in developing the flood disaster game-based learning. Through preliminary study showed that children were attracted to animation and audio. On the other hand, animation contributed largely to the world of learning where, the children experienced fun and entertaining [10]. In order to educate children, exposure on flood disaster issues should be concerned as well as focusing on their capabilities of learning through technology.

Children are exposed to the innovative technology at the early age where they learn by using computers. Apparently, the rapid development of technology itself has been proved that the children are able to practice their psychomotor skills and cognitive abilities [11], [12]. Children show interest in learning through the use of technology in daily lives which, different method of interaction attracts them well. In classroom, normally the preschool children are learning through static images with less physical movements and get bored easily. Hence, the new learning method by using computer was developed to convey the flood disaster education to young learners. This technology helped to improve their knowledge, awareness and fine motor skills. By providing learnable flood disaster game let the children experience enjoyment while learning.

Despite the growth development of preschool children, they could practice easily to use the keyboard and play with the flood disaster game-based learning. This practice led them to improve their speed of hand-eye coordination while playing. The preschool children can control their finger movements to interact with the computers. Therefore, preschool children at the age of six showed that they did not face any difficulties to use computer keyboard at all. A lot of practical training of using keyboard helped them to improve speediness and strengthen the finger muscles too.

In recognition of flood disaster education, there is a need to develop an interactive learning through game-oriented application. Flood disaster game-based learning used to educate the preschool children. Their cognitive, psychomotor and behavior towards flood disaster issues were taken seriously. This paper discussed on the design and evaluation of flood disaster game-based learning to achieve learnability with better understanding. Through gaming environment conveyed the knowledge by interactive learning tool provided for preschool children.

\section{METHOD}

The Model of Flood Disaster Game-Based Learning was developed based on the user requirements, previous model of game-based learning and flood disaster issues. Thus, a flood disaster game-based learning was designed and developed to validate the model through analysis, design, development, implementation and evaluation phase. These few phases illustrated as a cyclical and continuous process to improve instructional development.

\section{A. Analysis Phase}

Firstly, analysis phase involved the preschool children at the age of six in obtaining the user requirements. The previous studies investigated on acquiring their needs in order to develop the model of flood disaster game-based learning [7], [13], [14], [15], [16]. Layer, rules, reward, storyline, multimedia components (text, audio, animation), challenges, game genre (strategy), Malay language, user interaction, computer and keyboard are the elements of games needed in developing the model. Yet, this phase included the instructional goals and defining the problems of flood disaster issues.

By identifying the user requirements of preschool children, the data collected such as player, rules, reward, storyline, multimedia components, challenges, strategy game and Malay language would be implemented in developing the flood disaster game-based learning. These requirements let them use the computer technology with ease by using keyboard to learn flood disaster education.

\section{B. Design Phase}

Secondly, designing phase involved the outputs of analysis phase such as animation, storyline, background image, character, audio selection, activities of missions, font text, font colour and icons. Meanwhile, Adobe Illustrator and Adobe Photoshop were used in designing. For example, the character created was a boy that needed to accomplish all the missions. The target users were preschool children that attracted with the animation. Thus, the designer tend to create an animated child with various movements such as walking, jumping, dragging and dropping. Therefore, audio selection should be suitable with preschool children. It helped to change their mood with happiness and enjoyment. The background images were designed based on the flood disaster situation which divided into three levels of missions with the use of Malay Language completely.

Published By:

Blue Eyes Intelligence Engineering

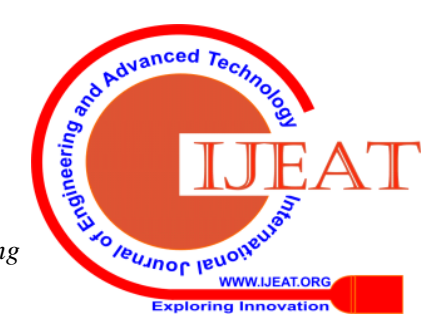


Figure 1 showed the model development of flood disaster game-based learning for preschool children. It involved the user requirements of preschool children such as type of technology used, their abilities in three main aspects (cognitive, psychomotor and behavior) and game elements that suitable for their ages.

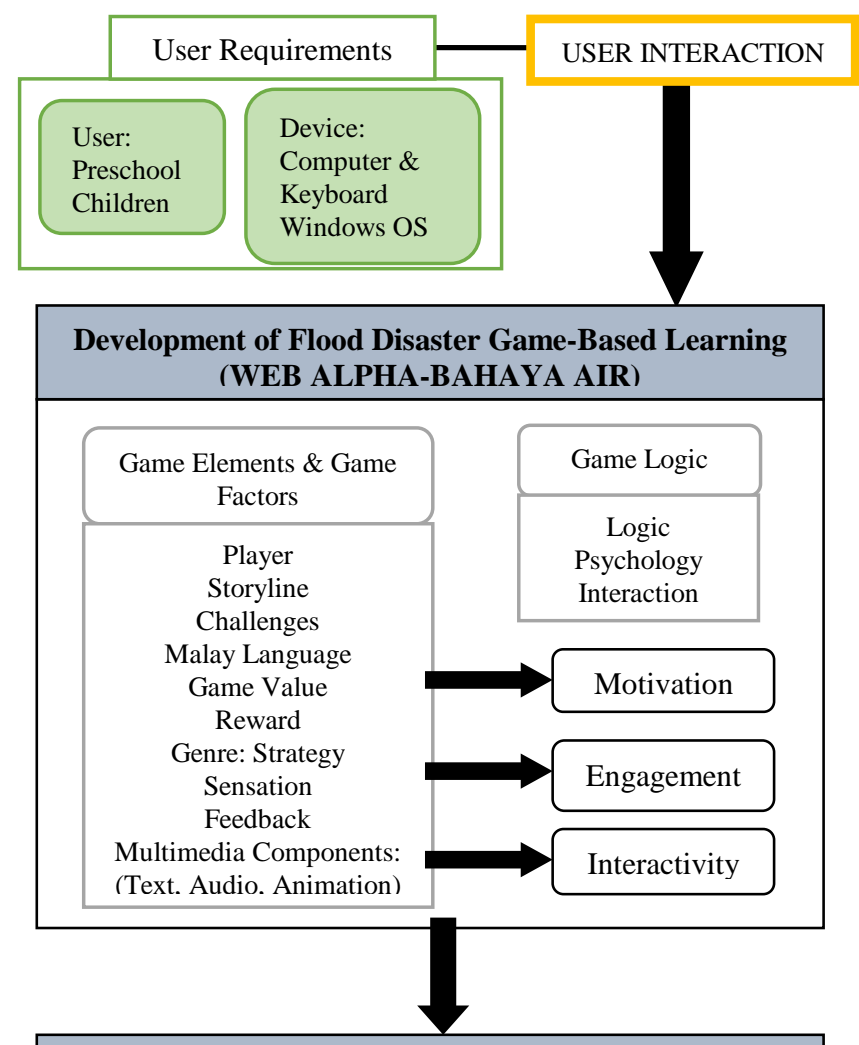

USABILITY EVALUATION: LEARNABILITY (Techniques Used: Observation \& Think Aloud)

Cognitive

To improve the motivation of learning through game-oriented. Every level of the missions tested on the preschool children to acquire and stimulate their abilities to complete the tasks.

Level 1: To test the users to find the hidden key and tasks to do before the flood occurs.

Level 2: To test the users to complete the tasks during the flood situation and find the hidden key to proceed to the next level.

Level 3: To test the users to complete the tasks after the flood situation.

\section{Psychomotor}

The speed of finger movements to control the character were observed and hand-eye coordination during playing time was observed too to improve their skills on handling technology.

\section{Behaviour}

Increase the awareness of the users towards flood disaster issues and engage the users to learn through interactive learning. Meanwhile, the users experienced enjoyment while learning.
Fig. 1.Model of Flood Disaster Game-Based Learning

Therefore, the preschool children at the age of six were the target users to convey the flood disaster issue through gaming environment. The devices used were computer and keyboard where the children did not face any difficulties to control the arrow buttons on the keyboard. In fact, their finger movements were able to control the speed of character movements in the game and able to train their fine motor skills too. Meanwhile, Windows OS platform was used to develop the game.

The game elements and game factors were focused in the game development such as player, reward, feedback, storyline, sensation, challenges, game value, strategy game genre, Malay language and multimedia components of text, audio and animation. These affected the motivation, engagement and interactivity of the preschool children to experience the interactive learning tool. Therefore, the game designs focused on logic, psychology and interaction. Logic implied engagement of players during play time. While, psychology implied the excitement and motivation the users would experience. Interaction showed the context and storyline match the operation of technology.

Lastly, the development of the flood disaster game-based learning would be evaluated the learnability to validate the model. There were two techniques used to conduct the experiment which, were observation and think aloud. On the other hand, the three aspects that would be evaluated were cognitive, psychomotor and behaviour of the preschool children towards flood disaster education. On cognitive aspect, the preschool children would be tested on three levels of missions that they needed to accomplish. Every level provided the children to think on problem solving before, during and after the flood disaster. While, psychomotor aspect implied on their abilities to work well with the buttons provided on the keyboard. Small area of actions by using fingers helped them to interact and improve their skills on handling technology very well. Therefore, behaviour aspect showed on their responses towards flood disaster education. Through gaming environment, the preschool children were engaged to learn in excitement where, they have short-span of attention while learning.

\section{Development Phase}

Thirdly, developing phase continued after the completion of designing flood disaster game-based learning. The model development of flood disaster game-based learning consisted of the elements and factors of game. The other user requirements of preschool children were added too based on their capabilities of handling computer and keyboard. The model developed would be validated based on the usability of learnability and behaviors of preschool children towards flood disaster education as shown in Figure 1 [7], [15], [16], [17], [18].

The concept of game designing was based on Super Mario Bros theme of playing. Construct 2 was used as a development software to conduct the functionality coding of the character and buttons. The specification of the system is more on 2D and less coding needed for the amateur programmer. It is also specialized on drag and drop functions. As shown in Table 1,

Published By:

Blue Eyes Intelligence Engineering

\& Sciences Publication

(C) CoDvriaht: All riahts reserved.

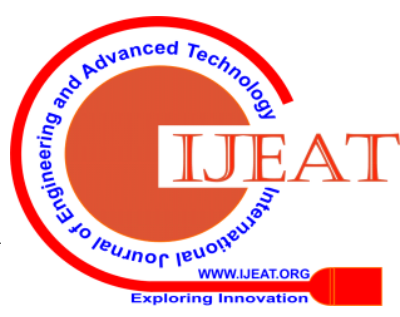


these were the flood disaster game-based learning interface design.

Table- I: Interface Design of WEB-ALPHA - "Bahaya Air"

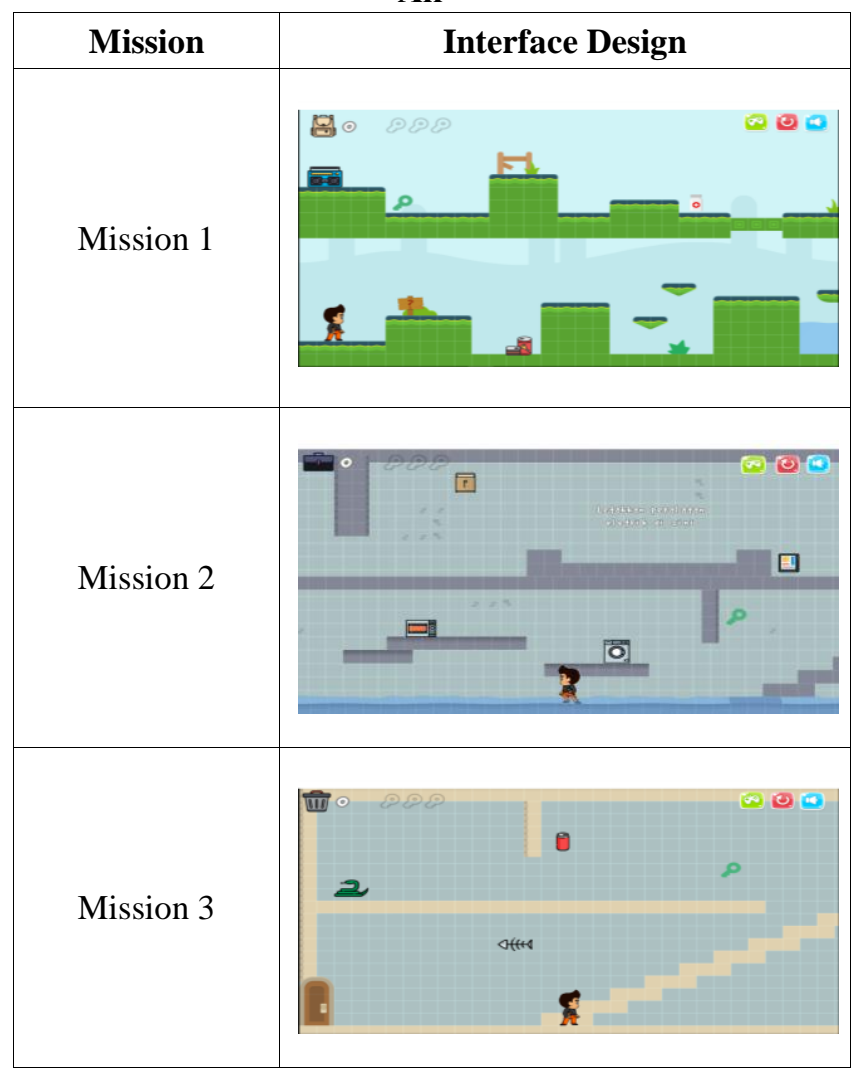

Next, the flood disaster game-based learning was known as "Bahaya Air". The first level of mission was about the player needed to bring along the important things before the flood. Meanwhile, the second level of mission was about the player needed to place all the electrical appliances at higher place to avoid damages during the flood. Lastly, the third level was about cleaning the house after the flood. These missions were testing the preschool children's capabilities to think the solutions and affecting their behaviors too.

In order for the player to proceed to the next level, the preschool children needed to find the three keys. Reward will be given to the player at the very end of missions. Following the instructions guided the player to play well as shown in Figure 2.

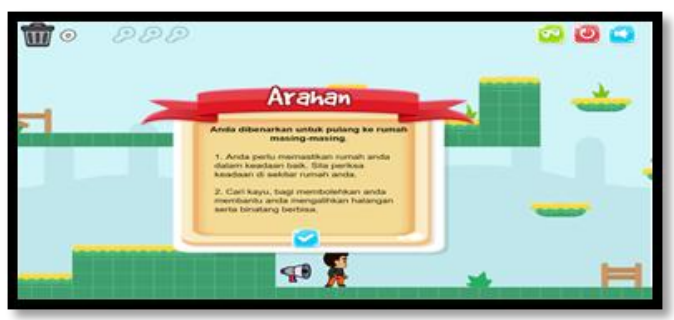

Fig. 2.Instructions of Mission

Figure 3 showed the player on how to interact with the computer keyboard. The player could control the movement of character in the game to the left, to the right and jump higher. While Figure 4 showed the items that should be collected in the missions.
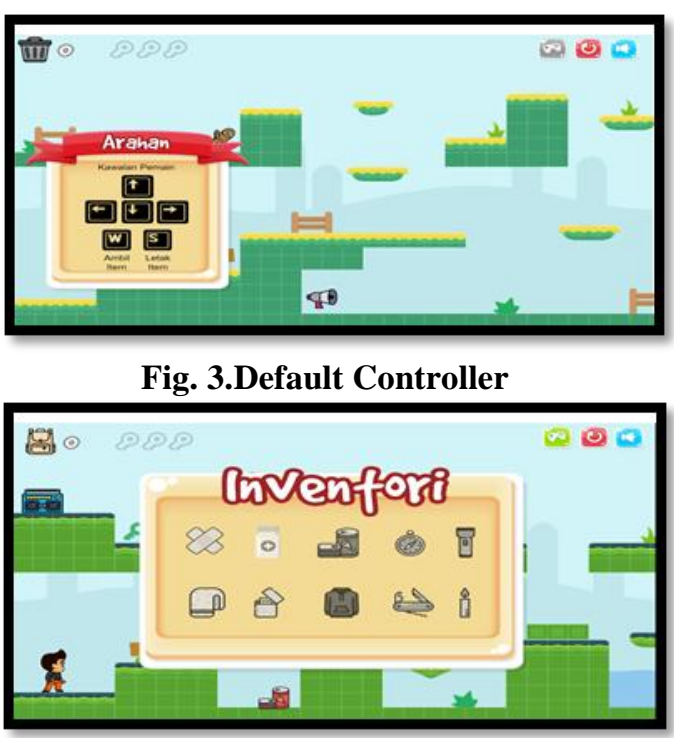

Fig. 4.Inventory of the Collected Items

Later, the players will be given reward at the very end of level to motivate them as shown in Figure 5. This led them to proceed to another level and engage them to play very well eventually and be competitive. The player would be notified on the score of collected items and congratulated for the successful missions of flood disaster game-based learning. Achieving the target improved their moods and turned into happiness. The decision making affected their actions on gameplay at every level as a key to success.

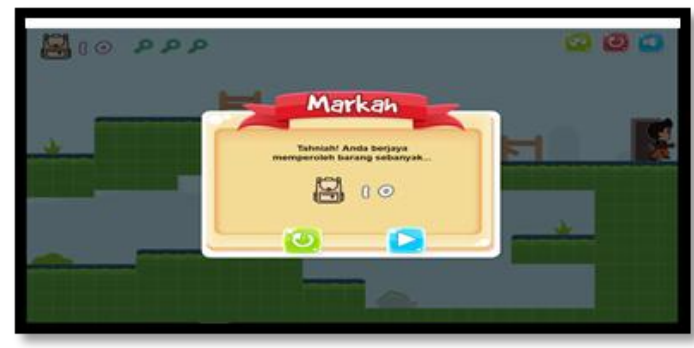

Fig. 5.Game Score

\section{Implementation and Evaluation Phase}

This evaluation phase consisted of flood disaster game-based learning's implementation and usability evaluation. The game was tested on ten children at the age of four to six years old to evaluate their capabilities on problem solving. Meanwhile, the learnability of the flood disaster game-based learning was the main focus for preschool children to educate them on flood disaster issues. There were three aspects would be evaluated on their capabilities of cognitive, psychomotor and behavior.

The cognitive aspect identified the stimulation of their brains in completing the missions. The preschool children were asked to read the instructions on how to play, control the default of arrow buttons and collect various type of items. While, their psychomotor of fine motor skills would be evaluated too.

Published By:

Blue Eyes Intelligence Engineering

\& Sciences Publication

(C) Copyright: All rights reserved.

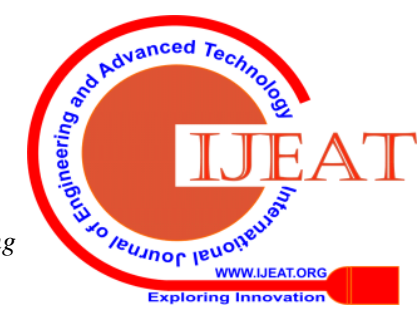


As mentioned, they have difficulties to control physical movements precisely due to the growth development of preschool children. However, with small area of action by using finger movements helped them to control the buttons easily. The stabilization of hand-eye coordination was also observed. Despite of the flood disaster awareness, the behaviors of preschool children were taken seriously to engage them in interactive learning.

Apparently, there were two techniques of investigation conducted which were, observation and think aloud [19], [20], [21]. Every action taken were observed and their feedback while playing the game that encouraged them. Table 2 showed the game score of ten preschool children tested.

Table- II: Score of The Game

\begin{tabular}{|c|c|c|c|}
\hline Respondent (R) & Level 1 & Level 2 & Level 3 \\
\hline R1 & $13 / 13$ & $14 / 16$ & $11 / 13$ \\
\hline R2 & $8 / 13$ & $11 / 16$ & $10 / 13$ \\
\hline R3 & $13 / 13$ & $16 / 16$ & $13 / 13$ \\
\hline R4 & $9 / 13$ & $13 / 16$ & $11 / 13$ \\
\hline R5 & $13 / 13$ & $16 / 16$ & $13 / 13$ \\
\hline R6 & $13 / 13$ & $16 / 16$ & $13 / 13$ \\
\hline R7 & $13 / 13$ & $14 / 16$ & $13 / 13$ \\
\hline R8 & $13 / 13$ & $15 / 16$ & $11 / 13$ \\
\hline R9 & $13 / 13$ & $13 / 16$ & $13 / 13$ \\
\hline R10 & $13 / 13$ & $16 / 16$ & $13 / 13$ \\
\hline
\end{tabular}

These scoring marks identified their abilities of thinking skills on how to complete the tasks. Every collectable items were shown in the bag provided to notify the player on finding the right items. On the other hand, the scoring marks obtained showed their capabilities to remember all the items. This experiment conducted would test their cognitive abilities in understanding the instructions and goals of flood disaster game-based learning. The preschool children would be reminded on right actions to do before, during and after flood disaster. They were following the instructions very well. They tried to complete the missions by collecting the items needed.

There were three aspects evaluated in this experiment such as cognitive, psychomotor and behavior. Table 3 showed the results of preschool children obtained when playing "Bahaya Air".

\section{Table- III: Data Collection}

\begin{tabular}{|l|}
\hline Results \\
\hline Cognitive \\
Most of the users showed that they could complete all the \\
missions provided in the game. Every level has its own \\
difficulty to be solved by them. They managed to collect \\
the items after the instructions on how to play given to \\
them. They did not face any difficulties on interpreting the \\
items collected where, they remembered the items well. \\
For Level 1, the users needed to find the items for flood \\
preparation and hidden keys to unlock the door. The users \\
could accomplish the mission given except for R2 and R4.
\end{tabular}

Retrieval Number: C6216029320/2020@BEIESP

DOI: 10.35940/ijeat.C6216.049420

Journal Website: www.ijeat.org
Some of them skipped the collectable items and went for the hidden keys. For Level 2, he users needed to complete the mission when flood disaster occurred. The right actions to do were being observed. Only a few of them managed to complete the level as the instruction followed such as R3, R5, R6 and R10. The hidden keys obtained to proceed to the next level. For Level 3, the users managed to get rid all unwanted items after the flood. They needed to clean up the mess as instructed.

Based on the observation, it showed that the users were able to complete all the tasks easily where, the use of animation, audio and interactivity stimulated their brains and engaged them to learn. Some of them jumped after completing the mission and receiving reward. Meanwhile, based on think aloud technique, the children responded on enjoying the game. For example, Yes, finish the game...to the right take it...I should find the key!...can I finish all the levels?..Help!

\section{Psychomotor}

During the gameplay, most of them did not face any difficulties to control the finger movements. They managed to handle all the buttons provided for them to go right, left, down, jump, drag and drop. Although they were still at the age of growth development process, this game provided the interaction with ease. Some of them were not using computer and keyboard regularly, however they showed on how capable they were in handling the technology very well. Their hand-eye coordination were stable too.

\section{Behaviour}

In order to educate the users on flood disaster issues, they learned through gaming environment which attracted them more. During the gameplay, it showed that the users gave feedback and good responses towards the flood disaster game. The main objectives were to increase awareness and provide them guidance when flood disaster occurred. Other than engagement of learning, the users were also experienced enjoyment through interactive learning. So by giving them knowledge on the preparations of flood disaster, they could apply in real lives. Practical training would help them too when the real situation is about to occur.

The exposure of flood disaster education at the early age helps the preschool children to improve their knowledge and behaviors. Advantages on learning this issue lead them to take the right actions, early preparations and save them eventually. They could avoid badly injuries and traumatizing with adequate trainings given to them.
Published By:

Blue Eyes Intelligence Engineering

\& Sciences Publication

(C) CoDvriaht: All riahts reserved.

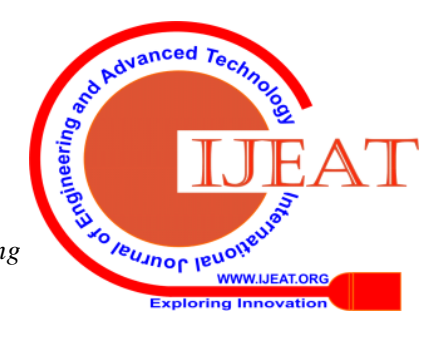




\section{DISCUSSION}

It is crucial that the engagement towards flood disaster education will improve the preschool children's performances and behaviors. Extending to this research, the tremendous growth of game-based learning was focused on flood disaster that strikes the development countries. Flood disaster could lead to the loss of property, physical effects and psychological of the victims. Therefore, game-based learning provided learning materials of game and education where, the preschool children learned the flood disaster issues that embedded in the game. It is necessary to develop an effective approach of flood disaster awareness.

Persuasive technology concept had been introduced to develop a learning approach of game-initiated learning (GIL). Players required to protect different areas that were affected by flood through selected engineering methods. In fact, the users could manage their thinking skills and strategies in decision making [1]. On the other hand, practicing game-based education could enhance the learning motivation that could affect the changes of implicit or explicit behavior.

Problem solving involved level of thinking and actions taken for the children to solve any difficulties. With the exposure towards flood disaster issues, absolutely they would think wisely on how to save themselves when flood disaster occurred. The development of game-based learning had been introduced as a learning approach where the concept of learning and playing were applied. This could have enhanced the children's interests in learning instead of only focusing on reading concept of learning. Due to the short attention span of the children, there is a need on exposing them towards variety of learning approaches. So that they will show the positive progresses in learning.

The growing interest of serious game introduced the concept of serious purpose design. Nzoia sub-basin implied on mobile phone location based game of flooding for citizens [22]. This game provided gaming environment in the form of simple, fun to play and challenging. It enhanced the learning of flood disaster issues among the players. The development of this game focused on three components which, were WIKI, location based feedback mechanism and location based game.

Advances in technology of learning introduced gaming as disaster preparation. The relationship between the genre of games and person's self-efficacy demonstrated the potential of digital games. Preparedness strategies involved the right actions taken to increase the awareness through playing the game. Consequently, the digital game enriched the excitement for the users to learn about disasters.

Thus, by developing the flood disaster game-based learning could improve their engagement in learning. In fact, every development process must fulfill the requirement needs. The preschool children who are in the growth development phase do have their own limitations compared to adults [23], [24]. In terms of these learning domain that were cognitive, psychomotor and behavior, the usability of learnability was evaluated on them. The use of flood disaster game-based learning could validate the model developed successfully.

\section{CONCLUSION}

This study reinforced the applicability of model development of flood disaster game-based learning. By applying the learning approach of game-based learning enhanced their motivation and interests to learn on flood disaster issues. Therefore, playing and learning could stimulate their brains at the same time. The exposure towards flood disaster issues should be started at the early age so that they would aware on these serious matters that involved the risk of lives.

The development of the model was not only focusing on playing but also to increase the awareness towards flood disaster issues. The children were highly risk exposure to danger because they were still in development processes. The development processes involved of growing muscles, brains, level of thinking and behavior. In order for the children to learn flood disaster issues, a learning approach of technology had been introduced. The use of technology by using computer and keyboard let the children to explore more and engage them well while playing and learning at the same time.

The children were easily distracted and have short span of attention. By providing the approach of playing and learning using technology helped them to focus more. Children have limited capabilities compared to adults. Meanwhile, the usability of learnability affected the preschool children's capabilities of cognitive, psychomotor and behaviors. As a result, preschool children were able to learn the flood disaster education through gaming as well as applying the practical training in their daily lives. This could help them to reduce injuries and stay alert on preparedness strategies.

\section{ACKNOWLEDGMENT}

This work was supported by Strategic Research Grant of KRA-2018-025, Faculty of Information Science \& Technology, Universiti Kebangsaan Malaysia.

\section{REFERENCES}

1. Wahyudin, D., \& Hasegawa, S., "The Role of Serious Games in Disaster and Safety Education : An Integrative Review,” 2017, pp. 180-190.

2. João Emílio Almeida, Faria, J. T. P. N. J., Faria, B. M., Rossetti, R. J. F., \& Coelho, A. L., "Serious games for the Elicitation of way-finding behaviours in emergency situations," Iberian Conference on Information Systems and Technologies, CISTI, 2014.

3. Zaini, N. A., Fadzilah, S., \& Siti, T., "Evaluation of APi Interface Design by Applying Cognitive Walkthrough," International Journal of Advanced Computer Science and Applications, vol. 10, 2019.

4. Mach, R., "Serious Gaming-Raising Awareness for Retention Measures and Flood Disasters(2)," Peer Reviewed Proceedings Digital Landscape Architecture, 2010.

5. Lin, S. C., Tsai, M., Chang, Y., \& Kang, S., "Game-Initiated Learning A Case Study For Disaster Education Research In Taiwan,” pp. 67-71, 2013.

6. Tsai, M. H., Chang, Y. L., Kao, C., \& Kang, S. C., "The effectiveness of a flood protection computer game for disaster education," Visualization in Engineering, vol. 3, 2015.

7. Bakhsh, S. A., "Using Games as a Tool in Teaching Vocabulary to Young Learners," English Language Teaching, vol. 9, 2016, pp. 120.

8. Rothkrantz, L. J. M., \& Fitrianie, S., "Public Awareness and Education for Flooding Disasters," Crisis Management - Theory and Practice, 2018.

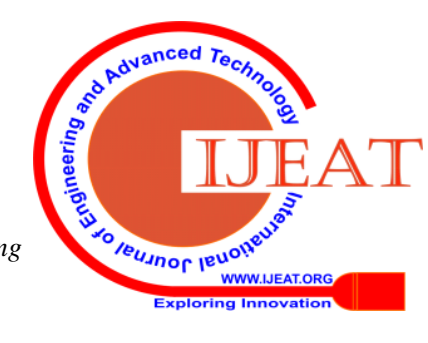


9. Kousky, C., "Impacts of natural disasters on children," Future of Children, vol. 26, 2016, pp. 73-92.

10. Ferreira, S. M., Gouin-Vallerand, C., \& Hotte, R., "Game based learning: A case study on designing an educational game for children in developing countries," 8th International Conference on Games and Virtual Worlds for Serious Applications, VS-Games 2016, 2016.

11. Noorhidawati, A., Ghalebandi, S. G., \& Siti Hajar, R., "How do young children engage with mobile apps? Cognitive, psychomotor, and affective perspective," Computers and Education, vol. 87, 2015, pp. 385-395.

12. Papadakis, S., Kalogiannakis, M., \& Zaranis, N., "Developing fundamental programming concepts and computational thinking with ScratchJr in preschool education: a case study," International Journal of Mobile Learning and Organisation, vol. 10, 2016, pp. 187.

13. Reich, S. M., Yau, J. C., \& Warschauer, M., "Tablet-based ebooks for young children: What does the research say?, Journal of Developmental and Behavioral Pediatrics, vol. 37, 2016, pp. 585-591.

14. Angelia, S., Ohta, N., \& Sugiura, K., "Design and Evaluation of Educational Kinesthetic Game to Encourage Collaboration for Kindergarten Children," 12th International Conference on Advances in Computer Entertainment Technology, 2015.

15. Abdul Jabbar, A. I., \& Felicia, P., "Gameplay Engagement and Learning in Game-Based Learning: A Systematic Review," Review of Educational Research, vol. 85, 2015, pp. 740-779.

16. Zaini, N. A., Noor, S. F. M., \& Wook, T. S. M. T., "The User Requirements of Game-Based Learning in Fire Safety for Preschool Children," Advanced Science Letters, vol. 24, 2018, pp. 7795-7799.

17. Shi, Y.-R., \& Shih, J.-L., "Game Factors and Game-Based Learning Design Model," International Journal of Computer Games Technology 2015, vol. 1, 2015.

18. Aitken, L. M., Marshall, A., Elliot, R., \& McKinley, S., "Comparison of "think aloud" and observation as data collection methods in the study of decision making regarding sedation in intensive care patients," International Journal of Nursing Studies, vol. 48, 2011, pp. 318-325.

19. Arsal, G., Eccles, D. W., \& Ericsson, K. A., "Cognitive mediation of putting: Use of a think-aloud measure and implications for studies of golf-putting in the laboratory," Psychology of Sport and Exercise, vol. 27, 2016, pp. 18-27.

20. Marley, S., Bekker, H. L., \& Bewick, B. M, "Responding to personalised social norms feedback from a web-based alcohol reduction intervention for students: Analysis of think-aloud verbal protocols," Psychol Health, 2016, pp. 1-18.

21. Xin Gang, B., Suhaila, Z., Hasherah, M. I., \& Meng Chun, L., “A Bahasa Malaysia Interactive Book App as a Speech-Language Therapy Tool for Children with Language Delay," vol. 6, 2017, pp. 23-37.

22. Onencan, A., Kortmann, R., Kulei, F., \& Enserin, B., "MAFURIKO: Design of Nzoia Basin location based flood game," Procedia Engineering, vol. 159, 2016, pp. 133-140.

23. Hussain, N. H., Tengku Wook, T. S. M., Mat Noor, S. F., \& Mohamed, H, "Children's Interaction Ability Towards Multi-Touch Gestures," International Journal on Advanced Science, Engineering and Information Technology, vol. 6, 2016, pp. 875.

24. Laili Farhana, M. I., Nadia Akma, A. Z., \& Maizatul Hayati, M. Y. "Touch Gesture Interaction of Preschool Children Towards Games Application Using Touch Screen Gadjet," Asia-Pacific Journal of Information Technology and Multimedia, vol. 4, 2015, pp. 47-58.

\section{AUTHORS PROFILE}

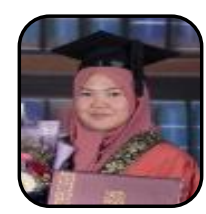

Nur Atiqah Zaini (Master of Information Technology., Universiti Kebangsaan Malaysia) was a postgraduate student and a researcher at E-learning lab, Centre for Software Technology and Management, Faculty of Information Science and Technology, Universiti Kebangsaan Malaysia (UKM). Her research interests encompass E-learning, Game-based learning, pre-school education and technology.

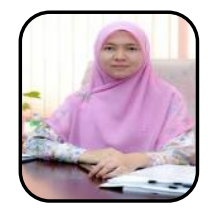

Siti Fadzilah Mat Noor (Ph.D., Universiti Teknologi Malaysia) is a senior lecturer and a researcher at Learning Technology and Human Computer Interaction Research Lab Centre for Software Technology and Management, Faculty of Information Science and Technology, Universiti Kebangsaan Malaysia (UKM). Her research interests encompass Multimedia Application and E-learning Technology.

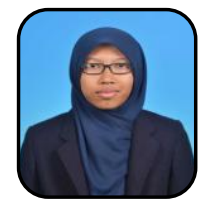

Syafiah Zahra Mohd Zailani (Degree in Software Engineering, Universiti Kebangsaan Malaysia) obtained her degree in Bsc Software Engineering (Multimedia System Development) from Faculty of Information Science and Technology, Universiti Kebangsaan Malaysia . Her research interests encompass game-based learning and learning technology.

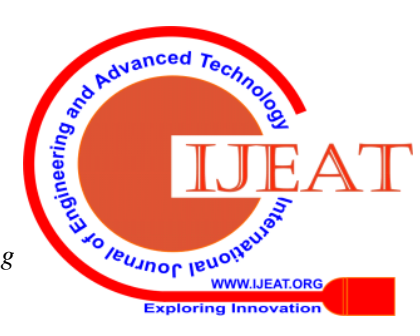

